\title{
A COMPARATIVE ASSESSMENT OF OPERATING CHARACTERISTICS OF A DIESEL ENGINE USING 20\% PROPORTION OF DIFFERENT BIODIESEL DIESEL BLEND
}

\author{
Senthil Ramalingam, Silambarasan Rajendran, Pranesh Ganesan \\ University College of Engineering Villupuram \\ Department of Mechanical Engineering \\ Kakuppam, Villupuram - 605103, India \\ e-mail:drrs1970@gmail.com
}

\begin{abstract}
The objective of the present work is to find out the viable substitute fuel for diesel and control of pollutants from compression ignition engines. Therefore, in this present investigation an attempt has been made to study the effect of $20 \%$ proportion of five different biodiesel diesel blend in diesel engine. The 20\% proportion of biodiesel such as Jatropha, Pongamia, Mahua, Annona and Nerium and 80\% of diesel and it is denoted as J20, P20, M20, A20 and N20 are used in the present investigation. The experimental results showed that the brake thermal efficiency of the different biodiesel blend is slightly lower when compared to neat diesel fuel. However, N20 blend, have shown improvement in performance and reduction in exhaust emissions than that of other biodiesel diesel blends. From, the experimental work, it is found that biodiesel can be used up to $20 \%$ and $80 \%$ of diesel engine without any major modification.

The conducted experiments were conducted on a four cylinder four stroke DI and turbo charged diesel engine using biodiesel blends of waste oil, rapeseed oil, and corn oil with normal diesel. The peak cylinder pressure of the engine running with bio diesel was slightly higher than that of diesel. The experiments were conducted on a four cylinder four stroke diesel engine using bio diesel made from corn oil.
\end{abstract}

Keywords: biodiesel diesel blend, performance, emission, diesel engine

\section{Introduction}

The various types of vegetable oil, animal fats, used frying oil, waste cooking oil, edible oils, and non-edible oils that can be used as alternate fuels for diesel. The exhaust emission such as $\mathrm{CO}$, $\mathrm{HC}$, and PM can be reduced considerably, while using biodiesel blends as a fuel [1]. The effects of blending a biodiesel with other fuels, with specific properties such as lubricity, cetane number, flash point, kinematic viscosity, oxidative stability, and exhaust emission were discussed. The biodiesel and its blends increase the NOx level in the exhaust emission [2]. The rapeseed oil biodiesel has lower smoke emission and higher brake specific fuel consumption compared to that of diesel fuel. The ignition delay for standard diesel, B20, B5, B70 and B100 fuels were calculated $8.5^{\circ}, 7.75^{\circ}, 7.25^{\circ}, 6.50^{\circ}$ and $5.75^{\circ} \mathrm{CA}$ respectively [3]. The $\mathrm{CO}$ emission of diesel is $0.09 \%$ but soya bean biodiesel and its blends are less than $0.05 \%$ at high engine load. The NOx was slightly higher for biodiesel and its blends and the peak cylinder pressure was higher compared to that of diesel fuel. The difference of NOx emission between diesel and biodiesel blends is not more than $100 / \mathrm{ppm}$. The peak cylinder pressures are $8.12 \mathrm{MPa}$ and $8.11 \mathrm{MPa}$ for biodiesel and diesel respectively [4]. The biodiesel blend showed performance very close to that of diesel fuel. Further, the ethanol and methanol blends yielded lower brake power, higher SFC and lower CO emission [5].

The conducted experiments were conducted on a four cylinder four stroke DI and turbo charged diesel engine using biodiesel blends of waste oil, rapeseed oil, and corn oil with normal diesel. The peak cylinder pressure of the engine running with bio diesel was slightly higher than that of diesel and this was due to advance combustion process initiated by higher lubrication effects of bio diesel. Further, the use of biodiesel increases the BSFC up to $15 \%$ due to its lower 
heating value, higher viscosity and density [6]. The experiments were conducted on a four cylinder four stroke diesel engine using bio diesel made from corn oil. The NOx emission was higher for biodiesel and its blends. Further, the $\mathrm{B} 100$ biodiesel reduced $15 \%, 40 \%$, and $30 \%$ for $\mathrm{CO}, \mathrm{CO}_{2}$ and $\mathrm{HC}$ emissions respectively when compared to diesel fuel at various operating conditions [7].The experimental study on a four stroke DI diesel engine using various bio diesels such as cotton seed oil, soya bean oil, sunflower oil, rapeseed oil, palm oil, corn oil and olive kernel oil and their corresponding methyl ester at the blend ratio of 10/90 and 20/80 were conducted. The tested bio diesel blends irrespective of the raw feed stock material used for their production, can be used safely in the diesel engine at small blending ratio along with normal diesel fuel [8]. The effect of vegetable oils and their methyl esters such as raw sunflower, raw cottonseed oil, raw soya bean oil and their methyl esters, refined corn oil, distilled opium poppy oil and refined rapeseed oil on the performance and emission characteristics of a four stroke, direct injection diesel engine was discussed. The vegetable oil methyl ester's performance and emission characteristics were closer to the diesel fuel and it can be used as a substitute for diesel fuel [9]. The experiments were conducted by using soybean oil, peanut oil, corn oil, sunflower oil, rapeseed oil, palm oil, palm kernel oil, and waste fried oil. The diesel engine fuelled with vegetable oil methyl ester could potentially produce the same engine power, but with a reduction in the exhaust gas temperature (EGT), smoke and total hydrocarbon (THC) emission and with a slight increase in nitrogen oxides (NOx) emission [10].

The increase in brake thermal efficiency and decrease in specific fuel consumption were observed in the case of esterified mahua oil (at 75\% mahua oil blends) compared to that of diesel fuel [11]. The emission of $\mathrm{CO}$ and $\mathrm{HC}$ were too low for mahua oil methyl ester and oxides of nitrogen were slightly lower compared with diesel. The thermal efficiency for mahua methyl ester is $28.31 \%$ and it is due to more oxygen content present in the biodiesel [12]. The thermal efficiency for mahua oil methyl ester was at par with diesel and significant drop in emission such as hydrocarbon, carbon monoxide and smoke emission. Further, the mahua is a renewable fuel having lower emission and the performance was similar to that of diesel [13]. The karanja oil (B100) reduced $\mathrm{CO}$ and smoke emissions by $50 \%$ and $45 \%$ respectively, while $15 \%$ increase in the NOx emission was observed with the same fuel. Further, the BTE for B100 and its blends was almost closer to the BTE of diesel fuel [14]. The performance and emission of a diesel engine fuelled with pongamia pinnata methyl ester (PPME) and its blends with the diesel fuel were discussed. The blends of PPME of 40\% (B40) could replace the diesel for diesel engine because of their low emission and better performance [15]. The experiments on the performance and emission characteristics of a single cylinder, naturally aspired, four stroke, DI diesel engine fuelled with cottonseed oil and its blends were conducted. The exhaust emission including PM, smoke and $\mathrm{CO}$ were reduced by $24 \%, 14 \%$ and $24 \%$ respectively and $10 \%$ increase in NOx emission for biodiesel [16]. There is a slight increase in BTE, BSFC and reduction in NOx and soot emission for using various blends of jajoba oil. Further, the engine performance can be improved while using jajoba methyl ester with minor modifications in the engine operating conditions such as injection timing and injection pressure [17]. The $\mathrm{HC}$ and $\mathrm{CO}$ emission for coconut biodiesel blends of $5 \%$ and $15 \%$ were reduced considerably and $\mathrm{CO}_{2}$ and NOx emission were increased with biodiesel blend ratio. Further, the coconut blend at $5 \%$ and $15 \%$ can be used with diesel as an alternate fuel [18]. The sesame oil with diesel fuel can be used as a fuel without any modification in the diesel engine. Further, the exhaust emission level for sesame oil was lower than that of diesel fuel, except NOx emission [19]. The brake thermal efficiency for pure diesel was $29.6 \%$ and for pure jatropha was $21.2 \%$ at full load. Further, the smoke, $\mathrm{HC}$, and $\mathrm{CO}$ emission were decreased and $\mathrm{NOx}$ and $\mathrm{CO}_{2}$ increased for jatropha fuel when compared to that of neat diesel fuel [20].

The experiments were conducted on a four stroke single cylinder CI engine using mustard oil and neem oil blend with the diesel fuel. The smoke, HC, and NOx emission were observed for biodiesel blend. The esterified mustard oil at $20 \%$ blend satisfies the important fuel properties as 
per ASTM specification [21]. The experiments were conducted on a single cylinder four-stroke water-cooled diesel engine using edible vegetable oils such as nerium, jatropha, pongamia, mahua and neem oil with diesel fuel. The diesel engine runs successfully at $20 \%$ blends without affecting the engine performance. Among, the various vegetable edible oils, nerium biodiesel showed better performance than the others. Further, the biodiesel showed lower smoke and HC and higher NOx emission [22]. The $20 \%$ blends of madhuca indica showed better performance than the pongamia pinnata and neat diesel fuel. The $\mathrm{HC}, \mathrm{CO}$ and smoke emission were reduced drastically for madhuca indica. However, the $\mathrm{CO}_{2}$ and $\mathrm{NO}_{x}$ emission slightly increased compared to Pongamia pinnata and neat diesel fuel [23]. The experiments were conducted on a single cylinder four stroke DI diesel engine using annona methyl ester (AME) and its blends with diesel. The AME at 20\% blend shows better performance and lower exhaust emission. Further, the $\mathrm{CO}$ and HC, smoke emission reduced considerably and NOx emission slightly increased for the various proportions of annona methyl ester [24].

\subsection{Summary}

Biodiesel is substitute for diesel fuel and one of the best ways to reduce the exhaust emissions without any modification in the existing engines. Biodiesel is used in standard diesel engine results substantial reduction in emission of unburned hydrocarbon, carbon monoxide, and particulate. Experiments were conducted using various biodiesels such as soya bean, peanut, sunflower, jatropha, mahua, coconut, rape, karanja, neem, mustard, linseed, cottonseed, and castor. However, very few experiments were conducted using combination of nerium, annona, jatropha, pongamia, and mahua. It is found that these biodiesels are easily available, cheaper and its properties are very closer to diesel fuel and if planned to use. Hence, in the present investigation an attempt has been made to the study the effect of $20 \%$ proportion of different biodiesel-diesel blend on performance and emission characteristics of diesel engine.

\section{Materials and methods}

\subsection{Biodiesel}

Biodiesel can be defined as the diesel oil, which is naturally prepared from vegetable oils and animal fats. It can be used either in its pure form or blended with various chemical concentrations as per the requirement of specifications. The properties of biodiesel are identical to that of the standard diesel. It does not contain sulphur or any other chemical pollutants. Due to this, it does not produce any harmful poisonous gases during combustion. At the same time, normal petrol and diesel oils produce large amount of harmful poisonous gases during combustion. Many experts predicted that the biodiesel would be used as the main fuel for powering domestic vehicles. An important advantage to be mentioned about biodiesel is that it produces $80 \%$ less carbon dioxide compared with normal petroleum fuel.

\subsection{Sources of Biodiesel}

Biodiesel can be derived from edible and non-edible oils. The edible oil has limitations when used in diesel engine. The non-edible oils have the advantages of use in diesel engine because of availability cheaper and they are not commercially used. These oils are derived from Jatropha Curcus, Pongamia Pinnata, Neem (Azadirachtaindica), Mahua, Castor, Linseed, Kusum Schlecheratrijuga), Annona, Nerium etc.

\subsubsection{Advantages of Biodiesel}

Biodiesel is an alternative to petroleum and diesel. It is eco-friendly, biodegradable, non-toxic, and free from sulphur, lead, and aromatics. It gives similar torque, horsepower, and mileage with 
diesel fuel. It is easy to store and handle. Due to its lubricating properties, engine parts function smoothly. It has increased life of the engine. Its detergent properties keep the injection fuel pump and filter clean. It has a very high flash point making it one of the safest of fuels and it gives higher combustion efficiency.

\subsubsection{Disadvantages of Biodiesel}

Biodiesel have drawbacks of short-term cold weather starting, plugging, and gumming in filters and lines, engine knocking, long-term choking of injectors, carbon deposits on piston and head of the engine, excessive engine wear, failure of engine lubricating oil due to polymerization.

Considering the above advantages, Nerium, Annona, Jatropha, Pongamia, and Mahua biodiesel are identified for the present study to conduct experiments in a DI diesel engine:

a) Jatropha - Jatropha carcass, locally known as ratanjyot, belongs to the family of Euphorbiaceae. A quick yielding plant survives in degraded, barren, forestland and drought prone areas and is cultivated as hedge on the farm boundaries. This oil is gaining popularity due to its good properties and has been accepted and recommended by National Biodiesel Board of India as a source of alternative fuel for blending in the commercial diesel.

b) Pongamia - Pongamia oil is derived from pongamia tree, found everywhere in India up to an altitude of $1200 \mathrm{~m}$ with a maximum height of $16 \mathrm{~m}$. Each shell of the fruit contains 1 to 2 kidney shaped brownish red kernels. It is non-edible oil. The oil is squeezed from the seeds (nuts) of pongamia containing in a shell.

c) Mahua - Mahua (Madhuca Indica) oil is a non-edible oil available in plenty in the tropical countries like India. The two major species of genus Madhuca found in India are MadhucaIndica (latifolia) and Madhucalongifolia (longifolia). This plant is common in deciduous forests. The seed and oil potential of this tree in India is varies from 180,000tons to 500,000 tons. Madhucalatifolia is a medium sized to large deciduous tree, distributed in South India, and evergreen forests.

d) Nerium - Nerium or Adelfa is an evergreen shrub that grows from 6 to 20 feet in tropical and subtropical areas worldwide including the Philippines. Its flowers may range in colour from white, pink, red, and any shade between them. Seeds are numerous and are compressed with a tuft of fine, shining white and greyish silky hair. Adelfa is used in traditional medicine for the treatment of ulcers, ringworms, leprosy, eczema, hemorrhoids, herpes simplex, and herpes zoster (skin shingles). It is also effective as skin insect repellant.

e) Annona - Annona squamosa is a member of the family of custard apple trees called Annonaceae and a species of the genus Annona known mostly for its edible fruits Annona. It is commonly found in India and cultivated in Thailand and originates from the West Indies and South America. It is mainly grown in gardens for its fruits and ornamental value. It is considered as beneficial for cardiac disease, diabetes hyperthyroidism, and cancer. The root is considered as a drastic purgative.

\subsection{Extraction of Biodiesel}

Three main methods have been identified for the extraction of the oil: Mechanical extraction, Solvent extraction and enzymatic extraction.

Mechanical and solvent extractions are the most common methods for commercial oil extraction. Before the oil extraction, the seeds have to be dried. Seed can be either dried in the oven at $105^{\circ} \mathrm{C}$ or sand dried for 3 weeks.

\subsubsection{Soxhlet extraction (laboratory scale)}

1. 50 grams of seeds are crushed and taken in the testing setup.

2. $150 \mathrm{ml}$ of methanol is taken in the round bottom flask as solvent. 
3. Reaction is kept at $65^{\circ} \mathrm{C}$.

4. Methanol recovered by retaining oil in round bottom flask.

5. Oil in the flask transferred to measuring beaker and measured.

6. The quantity of oil obtained is estimated to $1 \mathrm{~kg}$ of seeds roughly.

\subsubsection{Mechanical expeller (production scale)}

1. Seeds are crushed using mechanical expeller to get oil. (Mechanical expeller has the capacity of $30 \mathrm{~kg} / \mathrm{hr}, 3$ passes).

2. For a batch, $5 \mathrm{~kg}$ of seeds are taken to crush, each batch of seeds passed 5 times to obtain complete oil.

3. Oil obtained is collected in a glass reagent container by filtering it with filters.

4. Filtered oil is left for 10-12 hrs for settling of the minute dust particles.

5. After filtering and settling, oil is stored in a reagent glass bottle

In the present investigation, the requirement is limited; hence, the oil is extracted through soxhlet extraction method.

\subsection{Trans-Esterification Process}

The oil extracted from the above method has high viscosity. In order to reduce the viscosity trans-esterification process has to be done. The flow diagram of biodiesel production is shown in Fig. 1.

\section{BASIC TECHNOLOGY}

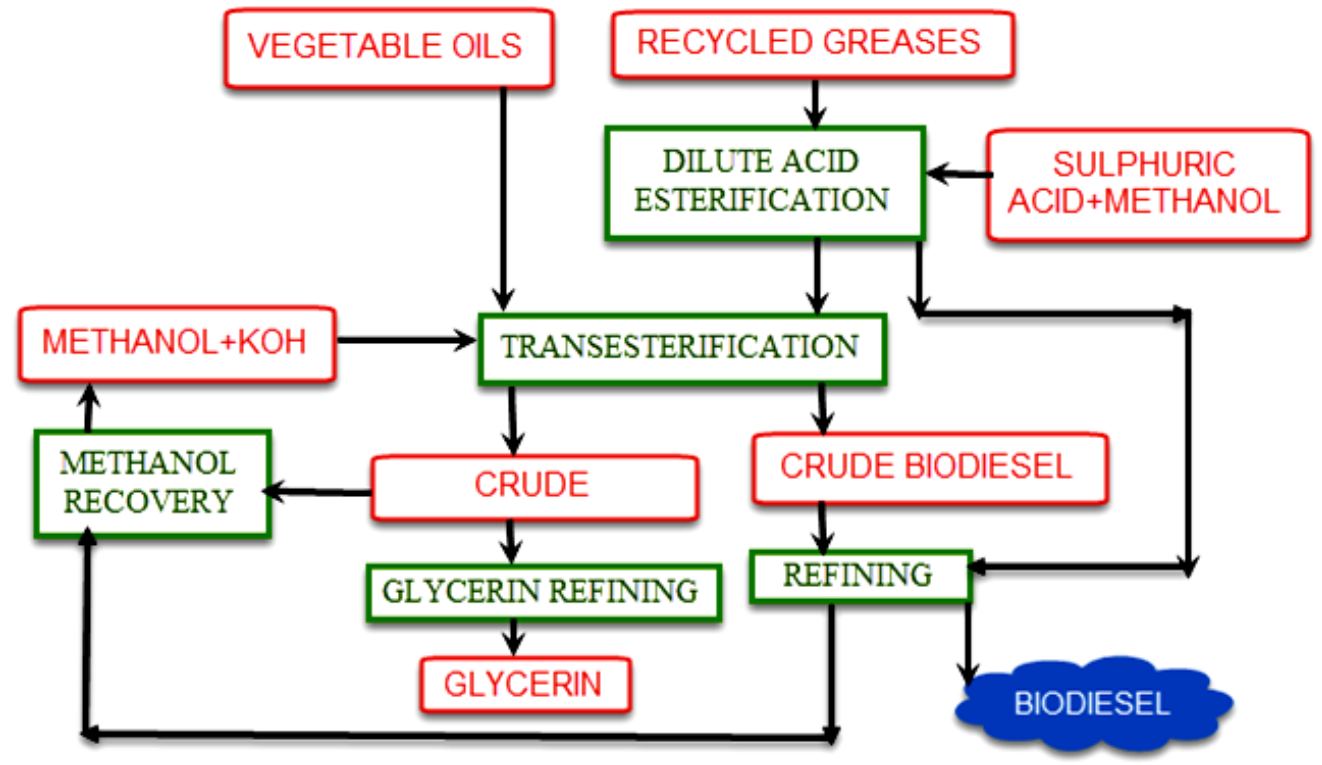

Fig. 1. Flow diagram of biodiesel production

The procedure involved in transesterification process is given below.

1. $1000 \mathrm{ml}$ of vegetable oil is taken in a three-way flask.

2. 12 grams of Sodium Hydroxide $(\mathrm{NaOH})$ pellets are mixed with $200 \mathrm{ml}$ of methanol $\left(\mathrm{CH}_{3} \mathrm{OH}\right)$ and is taken in a beaker.

3. The $\mathrm{NaOH}$ is stirred with the alcohol until dissolved.

The solution obtained is mixed with oil in three-way flask and it is stirred properly. The methoxide solution with oil is heated to $60^{\circ} \mathrm{C}$ to $65^{\circ} \mathrm{C}$ and it is continuously stirred at a constant rate for 1 hour by a stirrer. The solution is poured down to the separating beaker and is allowed to 
settle for 8 hours. The glycerine is settled at the bottom and the methyl ester is formed at the top (coarse biodiesel). Methyl ester is separated from the glycerine. This coarse biodiesel is heated above $100^{\circ} \mathrm{C}$ and maintained for $10-15$ minutes to remove the untreated methanol. Impurities like sodium hydroxide $(\mathrm{NaOH})$ etc. are still dissolved in the coarse biodiesel. These impurities are cleaned up by washing with $350 \mathrm{ml}$ of water for $1000 \mathrm{ml}$ of coarse biodiesel.

This processed biodiesel is the methyl ester of oil, which is subjected to conduct test evaluation in the diesel engine. The extracted oils obtained from the Nerium, Annona, Mahua, Pongamia and Jatropha are processed to convert into methyl ester through transesterification process. The general chemical reaction for biodiesel production is given below in Fig. 2.

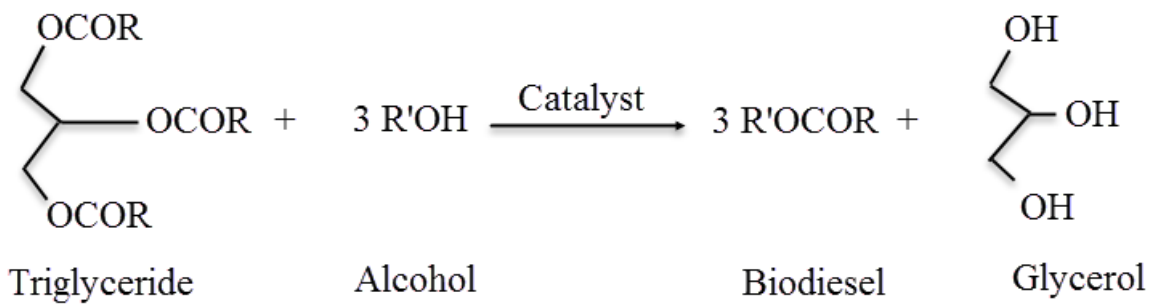

Fig. 2. Chemical reaction for biodiesel production

After transesterification process, the properties of methyl esters of different biodiesel are found in the laboratory at $20 \%$ blend are given in Tab. 1 .

Tab. 1. Properties of Diesel and 20\% Proportion of Different Biodiesel

\begin{tabular}{|l|c|c|c|c|c|c|}
\hline \multicolumn{1}{|c|}{ Property } & Diesel & N20 & A20 & J20 & P20 & M20 \\
\hline Kinematic viscosity in cst at $40^{\circ} \mathrm{C}$ & 3.1 & 3.2 & 3.35 & 3.41 & 3.45 & 3.76 \\
\hline Calorific value in $\mathrm{kJ} / \mathrm{kg}$ & 43200 & 43144 & 42660 & 41899 & 41842 & 41479 \\
\hline Density at $15^{\circ} \mathrm{C}$ in $\mathrm{kg} / \mathrm{mm}^{3}$ & 830 & 834 & 837 & 839 & 845 & 846 \\
\hline Cetane no. & 46.4 & 46 & 47 & 47 & 47 & 48 \\
\hline Flash point $\left({ }^{\circ} \mathrm{C}\right)$ & 56 & 59 & 60 & 62 & 62 & 63 \\
\hline Fire point $\left({ }^{\circ} \mathrm{C}\right)$ & 64 & 68 & 69 & 69 & 70 & 72 \\
\hline
\end{tabular}

\section{Experimental Procedure}

Experiments are carried out in a single-cylinder; water-cooled, naturally aspirated direct injection diesel engine coupled with an eddy current dynamometer. The schematic view of engine setup is shown in Fig. 3. The specification of the test engine is shown in Tab. 2. An eddy current dynamometer coupled to the engine is used as a loading device. The fuel flow rate, speed, load, exhaust gas temperature and gas flow rate are measured through data acquisition system. Gas Analyser is used to measure the CO, HC and NO emission. The specification of the exhaust gas analyser is shown in Tab. 3. Experiments are carried out at steady state for different engine loads at a speed of $1500 \mathrm{rpm}$. At each mode of operation, the engine is allowed to run for a few minutes until the exhaust gas temperature, the cooling water temperature, the lubricating oil temperature, as well as the emission have attained steady-state values and data are recorded subsequently. All the gas concentrations are continuously measured for 10 minutes and the average results presented. The steady-state tests are repeated thrice. The results of the three tests are found to agree with one another within the experimental data that lie outside the probability of normal variations will incorrectly offset the mean value, inflate the random error estimates. Uncertainty analysis is needed to prove the accuracy of the experiments. The percentage uncertainties of various 
parameters like load and brake thermal efficiency were calculated using the percentage uncertainties of various instruments shown in Tab. 4.

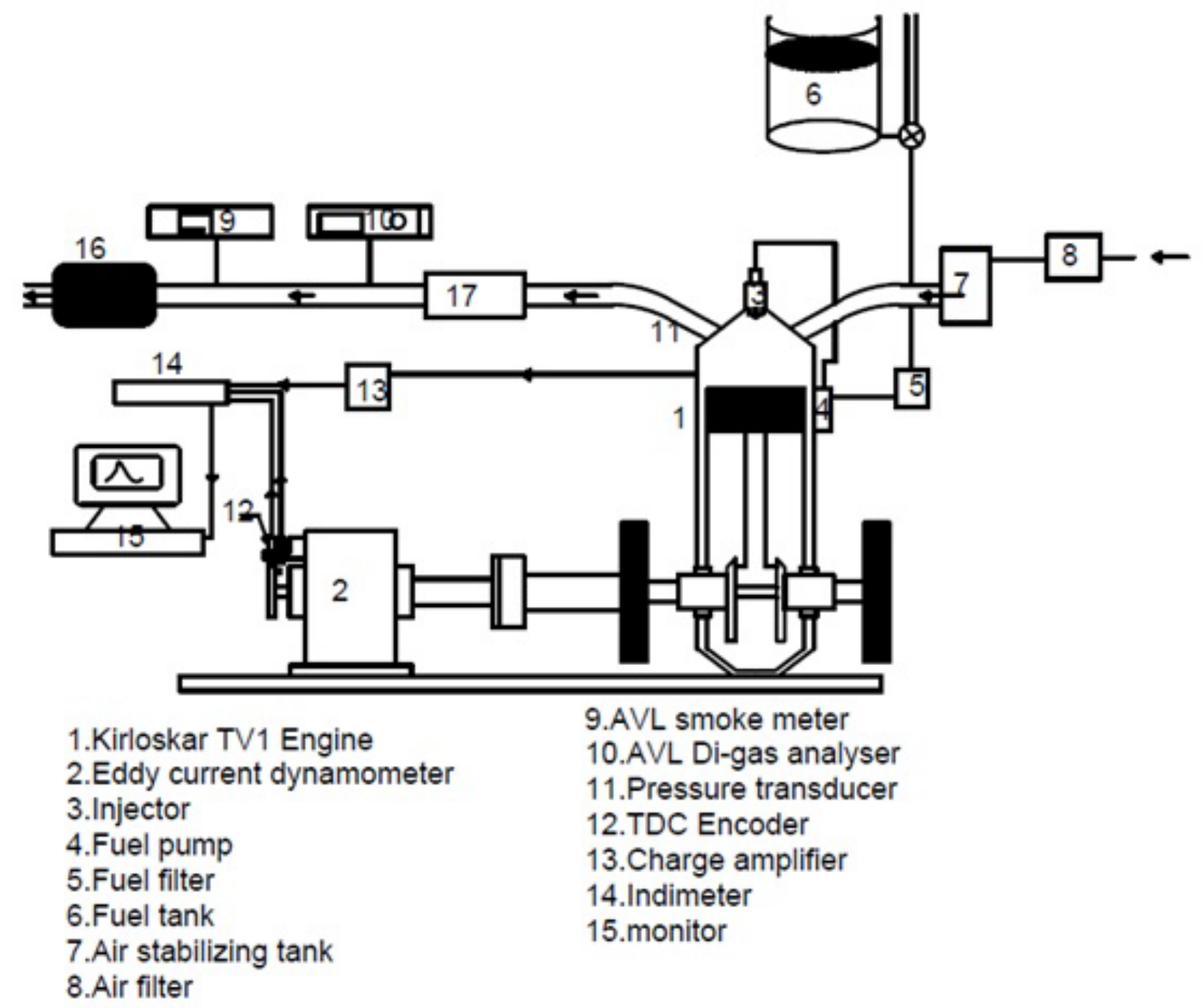

Fig. 3. Schematic view of engine setup

Tab. 2. The specification of the test engine

\begin{tabular}{|l|l|}
\hline Manufacturer & Kirloskar oil engines limited \\
\hline Model & SV1 \\
\hline Type of engine & $\begin{array}{l}\text { Vertical, 4-stroke cycle, single acting, single cylinder, } \\
\text { compression ignition diesel engine }\end{array}$ \\
\hline Displacement & $661 \mathrm{cc}$ \\
\hline Max brake power & $5.2 \mathrm{~kW}$ \\
\hline Speed & $1500 \mathrm{rpm}$ \\
\hline CR & $17.5: 1$ \\
\hline Lubrication system & Forced feed system \\
\hline Bore and stroke & $87.5 \times 110 \mathrm{~mm}$ \\
\hline Method of cooling & Water cooled \\
\hline Fly wheel diameter & $1262 \mathrm{~mm}$ \\
\hline Injection pressure & $200 \mathrm{bar}$ \\
\hline
\end{tabular}


Tab. 3. The specification of the exhaust gas analyser

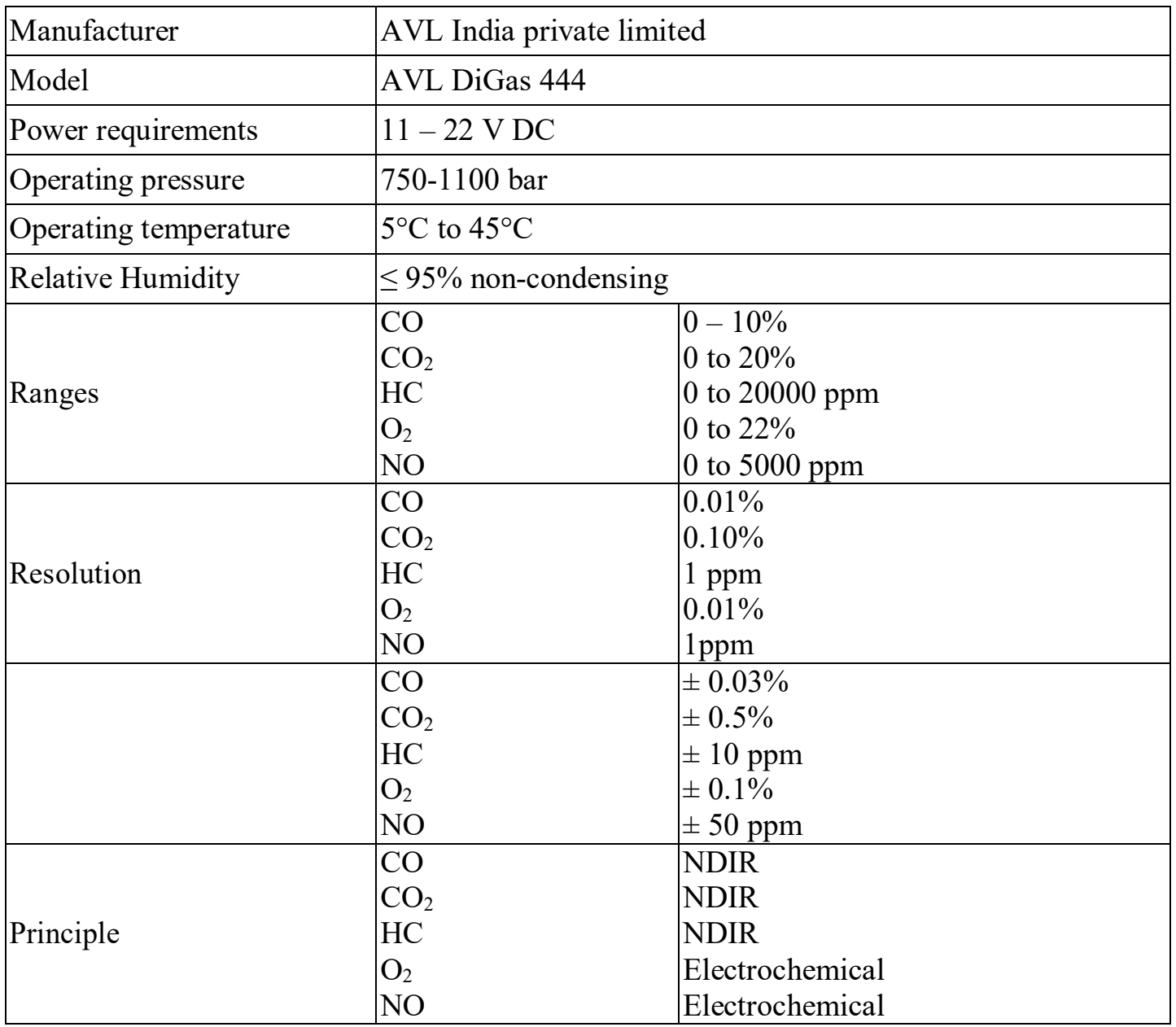

Tab. 4. Uncertainty in different parameters calculated at normal operating conditions and at full load

\begin{tabular}{|c|c|c|c|c|}
\hline \multirow[b]{2}{*}{ Parameters } & \multirow[b]{2}{*}{ Unit } & \multirow{2}{*}{$\begin{array}{c}\text { Standard } \\
\text { Deviation }(\sigma)\end{array}$} & \multicolumn{2}{|c|}{ Uncertainty $\Delta \mathbf{R}$} \\
\hline & & & Absolute & $\begin{array}{c}\text { Relative } \\
(\%)\end{array}$ \\
\hline $\begin{array}{l}\text { Fuel volume flow rate (time to consume } 10 \mathrm{cc} \\
\text { of fuel) }\end{array}$ & Seconds & 0.18 & \pm 0.1 & \pm 0.5 \\
\hline Total fuel consumption & $\mathrm{kg} / \mathrm{h}$ & 0.01 & \pm 0.005 & \pm 0.5 \\
\hline Peak pressure & bar & 1.58 & \pm 1 & \pm 1 \\
\hline Exhaust gas temperature & ${ }^{\circ} \mathrm{C}$ & 7.97 & \pm 3.6 & \pm 1.1 \\
\hline Oxides of nitrogen & ppm & 8.72 & \pm 4 & \pm 0.5 \\
\hline Hydrocarbons & ppm & 5.4 & \pm 2.5 & \pm 1.5 \\
\hline Carbon monoxide & $\%$ & 0.02 & \pm 0.008 & \pm 5 \\
\hline Smoke & HSU & 0.16 & \pm 0.07 & \pm 3 \\
\hline
\end{tabular}

\section{Results and discussion}

In this study of $20 \%$ proportion of jatropha, pongamia, manhua, annona and nerium methyl ester a have been investigated. The reasons for performance improvement and emission reductions were elaborately discussed in this section. 


\subsection{Specific fuel consumption (SFC)}

The variation of specific fuel consumption of N20, A20, J20, P20 and M20 biodiesel with brake power of the engine is shown in Fig. 4. It is observed that the specific fuel consumption is lower for N20 biodiesel and other biodiesel having higher SFC. SFC is $0.315 \mathrm{~kg} / \mathrm{kW}-\mathrm{hr}$ for N20 and $0.342 \mathrm{~kg} / \mathrm{kW}$-hr for M20 fuel at maximum load. This is due to nerium biodiesel having higher cetane number and lower density when compared with the other biodiesel, which in turn improves the combustion.

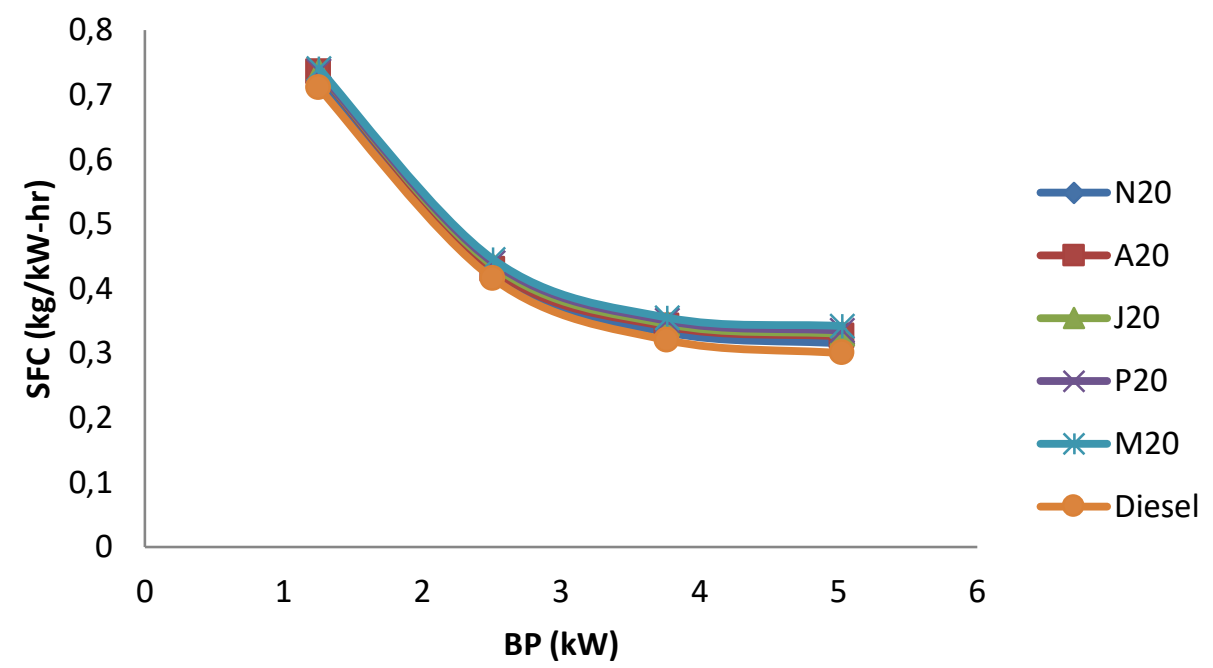

Fig. 4. Variation of SFC with BP for $20 \%$ proportion of different biodiesel

\subsection{Brake thermal efficiency (BTE)}

Figure 5 shows the variation of brake thermal efficiency of N20, A20, J20, P20 and M20 biodiesel with brake power of the engine. It is observed that BTE of different biodiesel is increasing with load. The maximum BTE of N20 is 30.8\% and for M20 is $28 \%$ and which is $2.8 \%$ higher than that of M20 biodiesel.

This is due to the higher cetane number for N20 and having inferior properties than the other biodiesel. Further, the density of N20 is lower than that of others, which is also the reason for improving the efficiency.

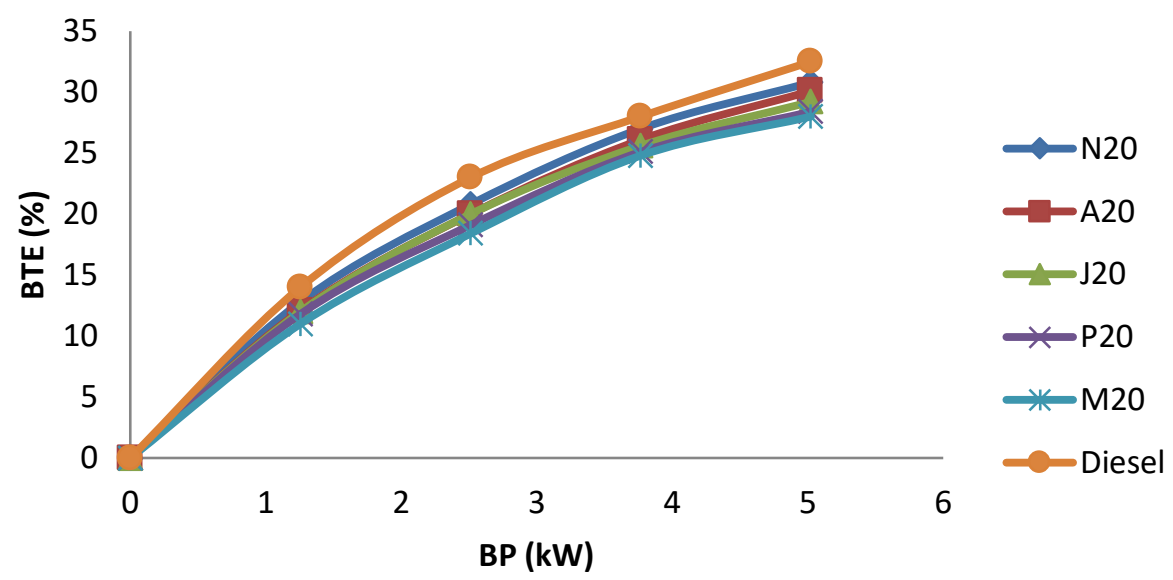

Fig. 5. Variation of BTE with BP for $20 \%$ proportion of different biodiesel 


\subsection{Exhaust gas temperature (EGT)}

Figure 6 shows the variation of exhaust gas temperature of N20, A20, J20, P20 and M20 biodiesel with brake power of the engine. It is observed that EGT of N20 is lower than that of other biodiesel. The maximum EGT of N20 is $195^{\circ} \mathrm{C}$ at full load, which is $20^{\circ} \mathrm{C}$ lower than that of M20 biodiesel. This is due to N20, which has higher heating value, lower density, and lower viscosity when compared with other biodiesel, and it leads to complete combustion.

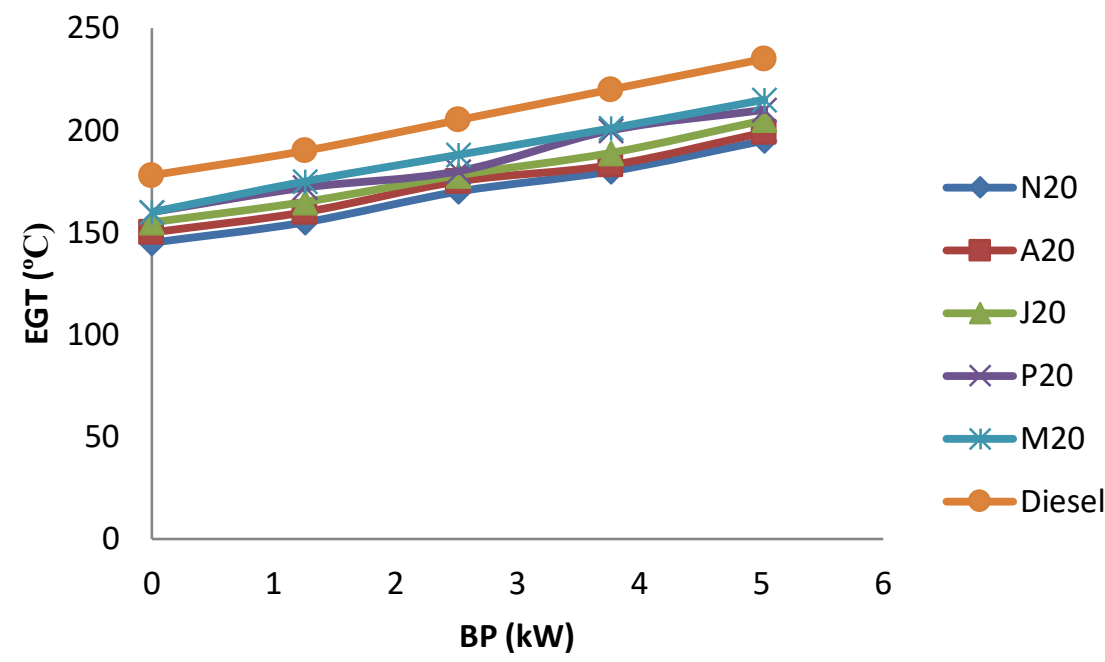

Fig. 6. Variation of EGT with BP for $20 \%$ proportion of different biodiesel

\subsection{Carbon monoxide emission (CO)}

The variation of carbon monoxide with brake power of the engine for N20, A20, J20, P20 and M20 biodiesel is shown in Fig. 7. It is found that $\mathrm{CO}$ emission for biodiesel decreases with increasing load. It has been seen that among all biodiesel blends, N20 has lower CO emission than that of other biodiesel. The CO emission for N20 is $0.10 \%$, which is $0.06 \%$ lower than that of M20 biodiesel at full load. The main reason for the reduction of $\mathrm{CO}$ in $\mathrm{N} 20$ biodiesel is due to the presence of more oxygen in nerium biodiesel and its higher combustion temperature. It is observed that among the five biodiesels, M20 shows the maximum emission of $\mathrm{CO}$ at all loads. This is mainly due to lower heating value and higher density than other biodiesel.

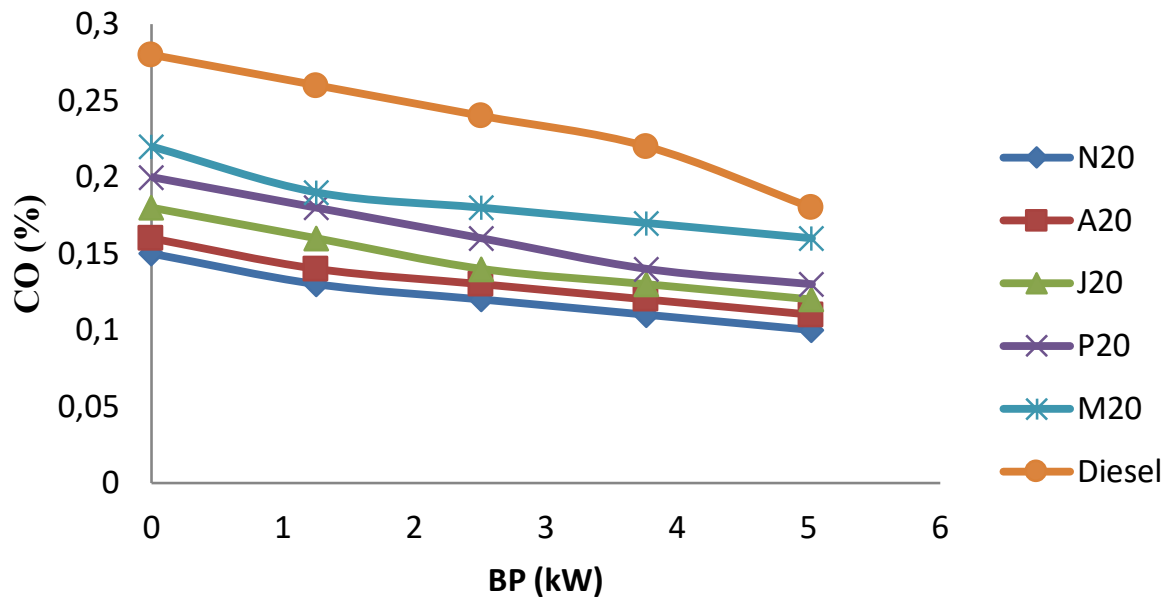

Fig. 7. Variation of CO with BP for $20 \%$ proportion of different biodiesel 


\subsection{Hydrocarbon emission (HC)}

Figure 8 shows the variation of hydrocarbon with the brake power of the engine for N20, A20, $\mathrm{J} 20, \mathrm{P} 20$ and M20 biodiesel. It is found from the graph that the $\mathrm{HC}$ emission decreases with increase in load. It is observed that among all biodiesel blend, N20 shows lower hydrocarbon emission and M20 shows higher hydrocarbon. It is also observed that $\mathrm{HC}$ for N20 is $18 \mathrm{ppm}$ and $28 \mathrm{ppm}$ for M20 at maximum load. This significant reduction of $\mathrm{HC}$ is due to complete combustion of $\mathrm{N} 20$ biodiesel in the presence of excess oxygen.

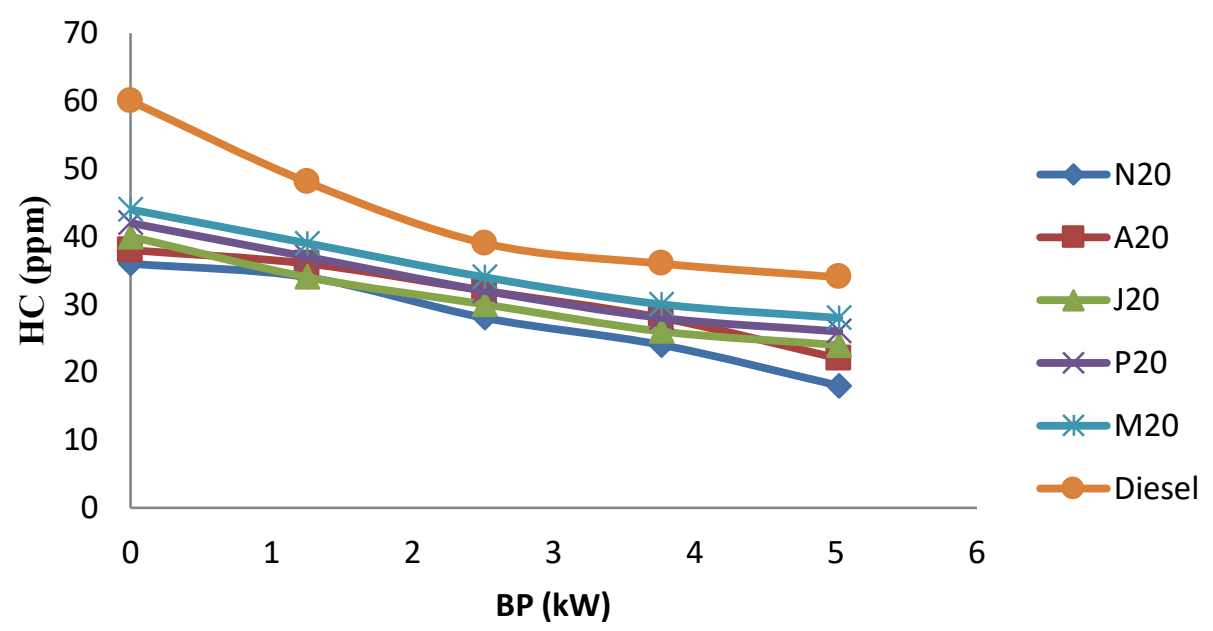

Fig. 8. Variation of HC with BP for $20 \%$ proportion of different biodiesel

\subsection{Oxides of nitrogen emission (NOx)}

The variation of oxides of nitrogen with brake power of the engine for N20, A20, J20, P20 and M20 biodiesel is shown in Fig. 9. It is found from the figure that $\mathrm{NO}_{\mathrm{x}}$ emission increases with the load and this is because of the increase in combustion chamber temperature with increase in load. It is observed that $\mathrm{NO}_{\mathrm{x}}$ emission for $\mathrm{N} 20$ is minimum when compared with other biodiesels blends at all loads.

It is also observed that $\mathrm{NO}_{\mathrm{x}}$ emission is $7.3 \%$ lower than that of M20 biodiesel at full load. This reduction of $\mathrm{NO}_{\mathrm{x}}$ emission is due to the presence of oxygen in N20 biodiesel reacting with hydrocarbon instead of nitrogen.

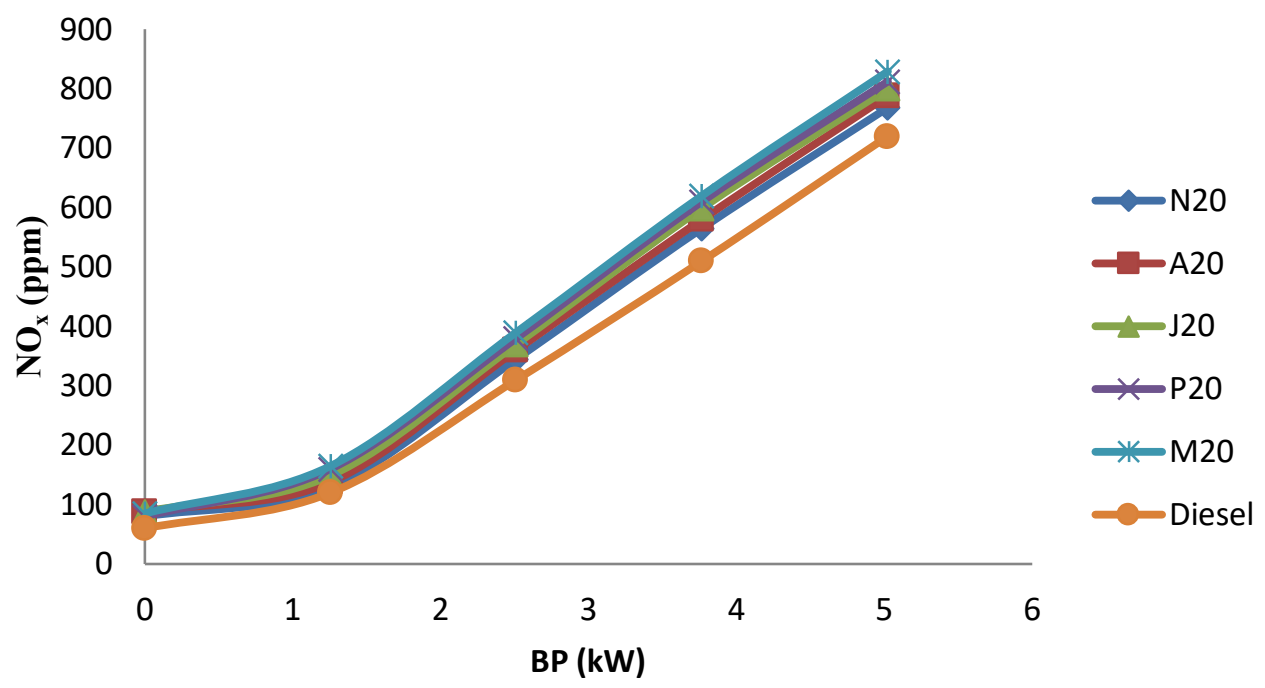

Fig. 9. Variation of NOx with BP for $20 \%$ proportion of different biodiesel 


\subsection{Smoke}

Figure 10 shows the variation of smoke with the brake power of the engine for N20, A20, J20, P20 and M20 biodiesel. Among the different biodiesel blends, N20 showed much lower smoke emission than the other biodiesel. It is observed that smoke of N20 is $10 \mathrm{HSU}$ and $14 \mathrm{HSU}$ for M20 biodiesel fuel at full load. The reduction of smoke is due to the higher heating value of N20 biodiesel and higher amount of dissolved oxygen present in the N20 biodiesel. This ensures complete combustion in the combustion chamber and in turn to a reduction in smoke emission.

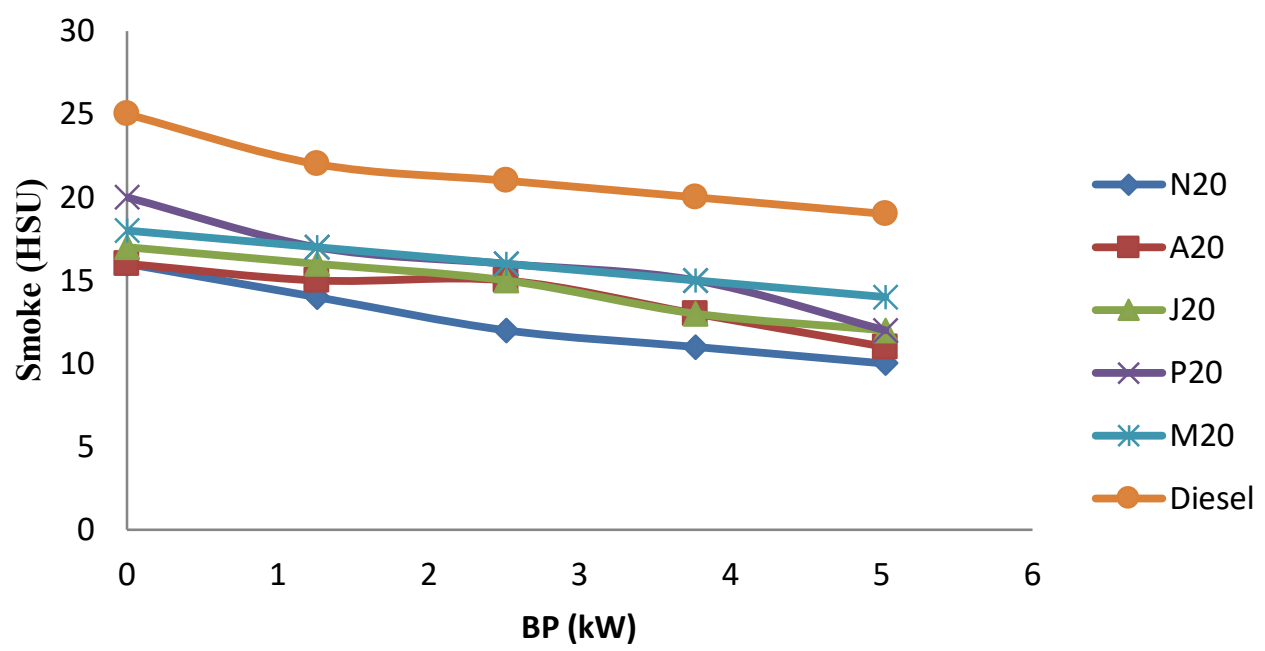

Fig. 10. Variation of Smoke with BP for 20\% proportion of different biodiesel

\section{Conclusion}

Experiments were conducted on a single cylinder, four-stroke, air cooled, direct injection diesel engine using $20 \%$ proportion of different biodiesel diesel blend and diesel. From the experiments the following conclusions are drawn.

1. Biodiesel blends showed slightly less performance than that neat diesel.

2. Biodiesel blends showed better reduction of all emissions except oxides of nitrogen. The oxides of nitrogen emission increase for all biodiesel and also increase with proportions of biodiesel blends.

3. Among the $20 \%$ proportion of various biodiesel, N20 showed better performance and reduced emission, however, at the expense of NOx emission.

Hence, it can be concluded that the $20 \%$ proportion of nerium biodiesel and $80 \%$ of diesel can be used in diesel engine without any major modification.

\section{Reference}

[1] Sharma, Y. C., Singh, B., Upadhyay, S. N., Advancements in development and characterization of bio-diesel: A review, Fuel, Vol. 87, pp. 2355-2373, 2008.

[2] Moser, B. R., Bio-diesel production, properties, and feed stocks', In: Vitro cell. Dev. Biol. Plant, Vol. 45, pp. 229-266, 2009.

[3] EkremBuyukkaya, Effects of bio-diesel on a DI Diesel engine performance, emission and combustion characteristics, Fuel, Vol. 89, pp. 3099-3105, 2010.

[4] Qi, D. H., Chen, H., Geng, L. M., Bian, Y. Z. H., Experimental studies on the combustion characteristics and performance of a direct injection engine fuelled with dio-diesel/ diesel blends, Energy Conservation and Management, Vol. 51, pp. 2985-2992, 2010. 
[5] Murat Karabekts, GokhanErgena, Murat Hosoz, Effects of the blends containing low ratios of alternative fuels on the performance and emission characteristics of a diesel engine, Fuel, Vol. 112, pp. 537-541, 2011.

[6] Tesfa, B., Mishra, R., Zhang, C., Gu, F., Ball, A. D., Combustion and performance characteristics of CI (Compression ignition) engine running with bio-diesel, Energy, Vol. 51, pp. 101-115, 2013.

[7] Belachew Tesfa, Fengshou Gu, Rakesh Mishra, Ball., A., Emission Characteristics of a CI engine running with a range of bio-diesel feed stocks, Energies, Vol. 7, pp. 334-350, 2014.

[8] Rakopoulos, C. D., Antonopoulos, K. A., Rakopoulos, D. C., Comparative performance and emission study of a direct injection diesel engine using blends of diesel fuel with vegetable oils or bio-diesel of various origins, Energy Conservation and Management, Vol. 47, pp. 3272-3287, 2006.

[9] Recep Altin, Selim Cetinkaya, Huseyin Serdar Yucesu, The potential of using vegetable oil fuel as fuel for diesel engines, Energy Conservation and Management, Vol. 42, pp. 529-538, 2001.

[10] Bai-Fu, Lin, Jyun-Han, Huang, Dao-Yi Huang, Experimental study of the effects of vegetable oil methyl ester on DI diesel engine performance characteristics andpollutant emissions, Fuel, Vol. 88, pp. 1779-1785, 2009.

[11] Sudheer Nandi, Performance of C.I engine by using Bio-diesel-Mahua oil, American Journal of Engineering Research, Vol. 2, No. 10, pp. 22-47, 2013.

[12] Sukumar Puhan, Vedaraman, N., Boppana, V. B., Ram, Sankaranarayanan, G., Jeychandran, K., Mahua oil (Madhucaindica seed oil) methyl ester as bio-diesel-prepartion and emission characteristics, Biomass and Bioenergy, Vol. 28, pp. 87-930 2005.

[13] Saravanan, N., Nagarajan, G., SukumarPuhan, Experimental investigation on a DI diesel engine fuelled with madhucaindica ester and diesel blend, Biomass and Bioenergy, Vol. 34, pp. 838-843, 2010.

[14] Nurun Nabi Md, Najmul Hoque, S. M., Shamin Akhter, M. D., Karanja (Pongamiapinnata) Bio-diesel production in Bangladesh, characterization of karanja biodiesel and its effect on diesel emissions, Fuel Processing Technology, Vol. 90, pp. 1080-1086, 2009.

[15] Suresh Kumar, K., Velraj, R., Ganesan, R., Performance and exhaust emission characteristics of a CI engine fuelled with pongamiapinnata methyl ester (PPME) and its blends with diesel, Renewable Energy, Vol. 33, pp. 2294-2302, 2008.

[16] Huzayyin, A. S., Bawady, A. H., Rady, M. A., Dawood, A., Experimental evaluation of diesel performance and emission using blends of jojoba oil and diesel fuel, Energy Conservation Management, Vol. 45, pp. 2093-2112, 2004.

[17] Nurun Nabi Md, Mustafizur Rahman Md, Shamim Akhter Md, Biodiesel from cottonseed oil and its effect on engine performance and exhaust emissions, Applied Thermal Engineering, Vol. 29, pp. 2265-2270, 2009.

[18] Liaquat, A. M., Masjuki, H. H., Kalam, M. A., Rizwanul Fattah, I. M., Hazrat, M. A., Varman, M., Mofijur, M., Shahabuddin, M., Effect of coconut biodiesel blended fuels on engine performance and emission characteristics, Procedia Engineering, Vol. 56, pp. 583590, 2013.

[19] Sehmus Altun, Husamettin Bulut, Cengizoner, The comparison of engine performance and exhaust emission characteristics of sesame oil-diesel fuel mixture with diesel fuel in a direct injection diesel engine, Renewable Energy, Vol. 33, pp. 1791-1795, 2008.

[20] Gaurav, P., Ambarish Datta, Bijiankumar Mandal, An experimental and numerical investigation of the performance combustion and emission characteristics of a diesel engine fuelled with jatropha biodiesel, Energy Procedia, Vol. 54, pp. 455-467, 2014.

[21] Anbumani, K., Ajit Pal Singh, Performance of mustard and neem oil blends with diesel fuel in C.I. engine, ARPN Engineering and Applied Sciences, Vol. 5, pp.14-20, 2010. 
[22] Prabhakar, S., Annamalai, K., Biodiesel: an alternative renewable energy for next century, Scientific \& Industrial Research, Vol. 70, pp. 875-878, 2011.

[23] Prabhakar, S., Annamalai, K., Isaac Joshuarameshlalvani, Experimental study of using hybrid vegtable oil blends in diesel engine, Scientific \& Industrial Research, Vol .71, pp. 612-615, 2012.

[24] Senthil, R., Silambarasan, R., Annona, A new biodiesel for diesel engine: a comparative experimental investigation, Journal of the Energy Institute, 88(4):459-69, 2014.

Manuscript received 09 January 2019; approved for printing 27 March 2019 